the majority of the literature has insufficient data on radiation dose exposure and patient-reported outcome comparisons between these two approaches.

Methods We retrospectively analyzed 198 patients who underwent diagnostic cerebral angiograms (DCA) at a community hospital from 5/1/2018 to $11 / 31 / 2020$ during the initial phase of adopting a TRA-first approach. Patients were grouped into two cohorts: TRA $(n=49)$ and TFA $(n=149)$. We compared radiation exposure parameters (total fluoroscopy time (FT), total radiation dose (TD), and dose area product (DAP), number of vessels injected, and patient-reported Global Health physical and mental outcome Scores (PRO GHS) at 30 days post-procedure. Also, a second radiation exposure comparative analysis was performed among patients who received a complete 6-vessel DCA.

Results Fluoroscopy time was significantly greater in TRA compared with TFA (15.5 min vs. $10.5 \mathrm{~min} ; \mathrm{p}<0.001)$. In addition, TRA had a significantly higher total dose $(286 \mathrm{mGy}$ vs. $220.3 \mathrm{mGy} ; \mathrm{p}=0.027)$ and dose area product $(3300.2$ $\mu \mathrm{Gym}^{2}$ vs. $2442 \mu \mathrm{Gym}^{2}$; $\mathrm{p}=0.027$ ) when compared with TFA. Analysis of only 6-vessel DCAs also showed that TRA had a significantly higher FT (18.4 vs $11, \mathrm{p}<0.001)$, DAP (3868 vs $2604, \mathrm{p}=0.01$ ), and TD (308.65 vs $224.5, \mathrm{p}=0.01$ ) in comparison to TFA.Despite observing a longer FT in TRA, results showed fewer vessels injected (TRA vs TFA; 5 vs 6, $\mathrm{p}=0.031$ ), and a notably lower success rate in acquiring a 6-

Variables Affecting Radiation exposure (FT) Graph showing how Age and Number of vessels injected affect FT in TRA \& TFA

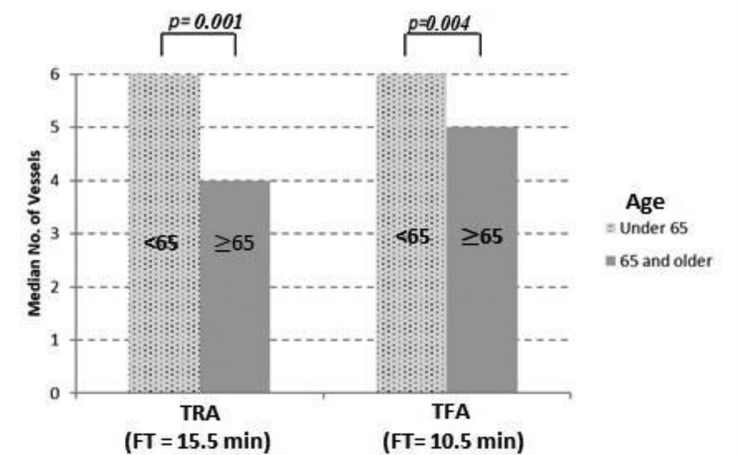

Highest radiation exposure was recorded in older patients with $<6$ vessels injected (With comorbid CVD) who underwent TRA.

Comorbid CVD and Age affecting higher FT in $<6$ vessel DCA in comparison to 6 Vessel DCA

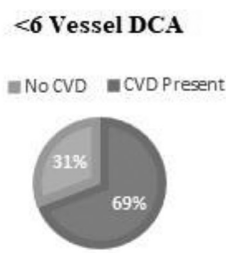

6 Vessel DCA
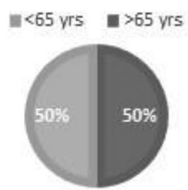

Abbreviations: $p$-p-value, TRA -Transradial Access, TFA -Transfemoral Access, CVD-Cardiovascular Diseases, $D C A$-Diagnostic Cerebral Angiography, FT -Fluoroscopy time,yrs- Years vessel DCA (TRA vs TFA; 36.7\% vs 55.7\%, $\mathrm{p}=0.065$ ) using the TRA technique. Further analysis of the effect of vessel number on FT using general linear models showed that with every increase of 1 vessel, the FT increases by $2.2 \mathrm{~min}$ for TRA $(\mathrm{p}<0.001 ; 95 \% \mathrm{CI}: 1.03-3.36)$ and by $1.3 \mathrm{~min}$ for TFA $(\mathrm{p}<0.001 ; 95 \%$ CI:0.72 - 1.83). There was no significant difference between groups in patient-reported GHS mental (TRA vs TFA; 53.3 vs $50.8, \mathrm{p}=0.509$ ) and physical (TRA vs TFA; 54.1 vs $50.8, \mathrm{p}=0.633$ ) t-scores at 30 days post-procedure, even though our cohort showed a significantly greater percentage of TRA procedures done in the outpatient setting (TRA vs TFA; $85.7 \%$ vs $57.1 \%$, p $<0.001$ ).

Conclusions Adopting a transradial first approach for diagnostic cerebral angiograms may be initially associated with longer procedure times and higher radiation dose for the patient. Better strategies are needed to mitigate this effect.

Disclosures C. Amankwah: None. L. Lombardo: None. J. Rutledge: None. A. Sattar: None. B. Chancellor: None. H. Moyle: None. D. Altschul: None.

\section{P-038 DEMOGRAPHIC DISPARITIES IN PROXIMITY TO CERTIFIED STROKE CARE IN THE UNITED STATES}

${ }^{1} \mathrm{C} \mathrm{Yu}^{*},{ }^{2} \mathrm{~T}$ Blaine, ${ }^{1} \mathrm{P}$ Panagos, ${ }^{1,2} \mathrm{~A}$ Kansagra. ${ }^{1}$ Washington University School of Medicine, St Louis, MO; ${ }^{2}$ Mallinckrodt Institute of Radiology, St. Louis, MO

\subsection{6/neurintsurg-2021-SNIS.74}

Introduction The geographic distribution of certified stroke centers is variable, which potentially creates disparities in access to stroke care between demographic groups that are geographically clustered. Demographic disparities in proximity to stroke care remain understudied at the national level. This cross-sectional study quantifies the relationship between distance to the nearest certified stroke hospital and censusderived demographics.

Materials and Methods We included population data by census tract from the 2014-2018 United States Census Bureau's American Community Survey, stroke hospitals certified by a state or national body and providing intravenous thrombolysis, and geographic data from a public mapping service to estimate road distances. Data were retrieved March-November 2020. Quantile regression analysis was used to compare relationships between road distance to the nearest stroke center for each census tract and tract-level demographics of age, race, ethnicity, medical insurance status, median annual income, and population density.

Results 2,388 stroke centers and 71,929 census tracts encompassing 316,995,649 individuals were included. 49,918 (69\%) tracts were urban. Demographic disparities in proximity to certified stroke care were greater in non-urban areas than urban areas. Higher representation of individuals aged $\geq 65$ years was associated with increased median distance to a certified stroke center in non-urban areas $(0.51$ $\mathrm{km}$ per $1 \%$ increase in population [99.9\% CI: 0.42, 0.59]), but not in urban areas $(0.00 \mathrm{~km}$ per $1 \%$ increase in population $[-0.01,0.01])$. In urban and non-urban tracts, median distance was greater with higher representation of American Indian (urban: $0.10 \mathrm{~km}$ per $1 \%$ increase [0.06, 0.14]; nonurban: $1.06 \mathrm{~km}[0.98,1.13])$ or uninsured populations $(0.02 \mathrm{~km}[0.00,0.03] ; 0.27 \mathrm{~km}[0.15,0.38])$. Each \$10,000 increase in median income was associated with a decrease in median distance of $5.04 \mathrm{~km}[4.31,5.78]$ in non-urban 
tracts, and an increase of $0.17 \mathrm{~km}[0.10,0.23]$ in urban tracts.

Conclusions Disparities in proximity to stroke care were worse in non-urban areas than in urban areas. Non-urban census tracts with greater representation of elderly, American Indian, or uninsured persons, or low median income, were substantially more distant from certified stroke care. Quantifying disparities in proximity to timely stroke care can inform ongoing efforts for infrastructure improvements that reduce inequalities in access to care.

Disclosures C. Yu: None. T. Blaine: None. P. Panagos: None. A. Kansagra: None.

\section{P-039 FLOW DIVERTERS FOR TREATMENT OF ICA LOOP DISSECTIONS OR ICA DISSECTIONS WITH ASSOCIATED PSEUDOANEURYSM}

'J Singh*, ${ }^{1} \mathrm{~A}$ Kuhn, ${ }^{2} \mathrm{~K}$ de Macedo Rodrigues, ${ }^{1} \mathrm{~F}$ Massari, ${ }^{1} \mathrm{M}$ Gounis, ${ }^{1} \mathrm{~A}$ Puri. ${ }^{1}$ Division of Neurointerventional Radiology, Dept of Radiology, New England Center for Stroke Research, University of Massachusetts Medical Center, Worcester, MA; ${ }^{2}$ Greensboro Radiology, Greensboro, NC

\subsection{6/neurintsurg-2021-SNIS.75}

Purpose Cervical internal carotid artery (ICA) loop dissections or dissections with associated pseudoaneurysm can pose a treatment challenge. Flow diverters are able to reconstruct vessel loops, treat the injured vessel and exclude an associated pseudoaneurysm from the parent artery.

Material and Methods We retrospectively reviewed our prospectively maintained Neuro IR database and identified all patients with ICA dissections primarily treated with flow diverters between July 2017 and September 2020. Patient demographics, procedural data, imaging follow up results and clinical outcome information was also collected.

Results A total of 11 patients were identified (9 males) with a mean age of 59.2 years (range 43 - 85 years). The patients had 7 ICA loop dissections with associated pseudoaneurysm in 2 cases, 3 focal ICA dissections with associated pseudoaneurysm and one long segment ICA dissection with associated pseudoaneurysm. Six lesions were treated with the Surpass Streamline flow diverter and 5 with the Pipeline Embolization device. A single flow diverter was placed in 4 cases, two flow diverters were placed in 1 case, combination of flow diverters and (carotid) stents were placed in the remaining cases and are listed in table 1. Two patients were lost to follow up and another 2 have not reached their follow-up time point yet. Two patients died, one as a result from his stroke burden with which he initially presented and one patient due to a large intraparenchymal hematoma in the setting of dual antiplatelet therapy. Three to 6-month angiogram follow up is available in 4 patients which showed near complete pseudoaneurysm occlusion in 2 cases and complete occlusion in the other 2 cases (figure 1); all cases

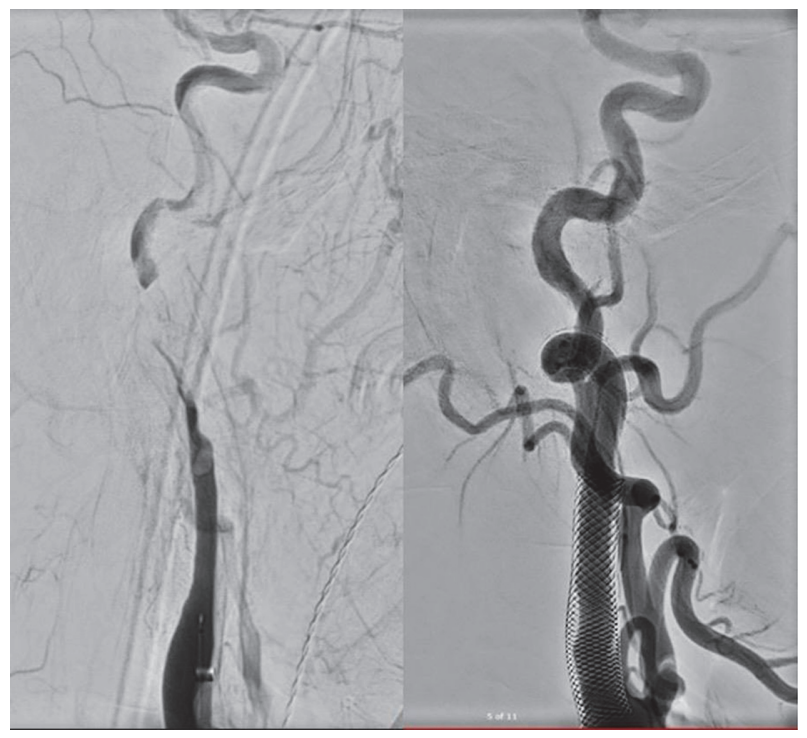

Abstract P-039 Figure 1

\begin{tabular}{|c|c|c|c|c|c|c|c|c|}
\hline Patient & Laterality & Presentation & Dissection & FD and Size(s) & Stent(s) & Follow up time & Follow up result & $\begin{array}{l}\text { Last known } \\
\text { mRS }\end{array}$ \\
\hline 1 & Right & Stroke & Loop dissection & Surpass $5 \times 40,5 \times 30$ & Wallstent $8 \times 36$ & Lost to follow up & - & 2 \\
\hline 2 & Left & Stroke & Loop dissection & Surpass $5 \times 40$ & Wallstent $8 \times 36$ & - & - & 6 \\
\hline 3 & Right & Stroke & Loop dissection & Surpass $5 \times 40,5 \times 40$ & Wallstent $8 \times 36$ & Not reached & - & 0 \\
\hline 4 & Left & Stroke & Loop dissection & Surpass $5 \times 50,5 \times 40$ & - & Lost to follow up & & 0 \\
\hline 5 & Left & Stroke & $\begin{array}{l}\text { Loop dissection with } \\
\text { pseudoaneurysm }\end{array}$ & Surpass $4 \times 50$ & - & Not reached & & 2 \\
\hline 6 & Left & Stroke & $\begin{array}{l}\text { Focal dissection with } \\
\text { pseudoaneurysm }\end{array}$ & Surpass $5 \times 30$ & - & 6 months & $\begin{array}{l}\text { No residual, patent } \\
\text { device }\end{array}$ & 3 \\
\hline 7 & Right & Stroke & $\begin{array}{l}\text { Focal dissection with } \\
\text { pseudoaneurysm }\end{array}$ & Pipeline $4.75 \times 25$ & - & - & - & 6 \\
\hline 8 & Right & Neck pain & $\begin{array}{l}\text { Focal dissection with } \\
\text { pseudoaneurysm }\end{array}$ & $\begin{array}{l}\text { Pipeline } 5 \times 16,4.75 \times 18, \\
4.75 \times 18,4.75 \times 16\end{array}$ & Acculink $6 \times 20$ & 6 months & $\begin{array}{l}\text { Near complete, patent } \\
\text { devices }\end{array}$ & 0 \\
\hline 9 & Right & Headache & $\begin{array}{l}\text { Long segment dissection with } \\
\text { pseudoaneurysm }\end{array}$ & Pipeline $5 \times 35,5 \times 33$ & Precise $5 \times 20$ & $\begin{array}{l}6 \text { months and } 20 \\
\text { months }\end{array}$ & $\begin{array}{l}\text { Complete occlusion, } \\
\text { patent devices }\end{array}$ & 0 \\
\hline 10 & Right & Stroke & Loop dissection & Pipeline $4 \times 25$ & $\begin{array}{l}\text { Neuroform EZ } \\
\text { Enterprise }\end{array}$ & 3 months & $\begin{array}{l}\text { Near complete, patent } \\
\text { devices }\end{array}$ & 0 \\
\hline 11 & Left & Stroke & $\begin{array}{l}\text { Loop dissection with } \\
\text { pseudoaneurysm }\end{array}$ & Pipeline $5 \times 35$ & - & 12 months & $\begin{array}{l}\text { Complete occlusion, } \\
\text { patent devices }\end{array}$ & 3 \\
\hline
\end{tabular}

